\title{
Abdominal obesity and their association with total body: fat distribution and composition. Case of Algerian teenager male high school students
}

\author{
Zerf Mohammed, Atouti Noureddine, Ben Farouk Abdullah \\ Physical Education Institute Laboratory OPAPS, University of Mostaganem, Algeria
}

\begin{abstract}
Purpose:

Our aim attempted to esteem the impact of abdominal fat on body fat distribution or composition related to total body fat as recommended weight loss among High School Students.

Material: $\quad$ For the proposed, 100 male students from the Algerian high school Education Sector's mandate Sidi Bel Abbes,

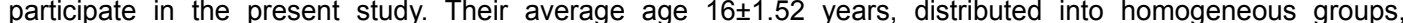
according to their body fat percent categories. Examined by saving tests (Body Fat Percentage (BFP) - Abdominal circumference (WC) - Body mass index (BMI)).

Results: $\quad$ Based on the test data and the analysis statistics applied, we confirm: a) Abdominal obesity is excess body gain correlate with total fat BMI. It highly affected body composition reported as additional fat for overweight in compare with acceptable according to Ideal BFP categories; b) Abdominal obesity is an amount deep fat correlates to total BFP. It higher influenced the distribution of total body fat reported as additional excess fat among overweight category compared to the acceptable group; c) Waist circumference (WC) is the leading marker of abdominal fat deposits located in the central region of the body. While the combination of body mass index (BMI) and waist circumference (WC), reflects the combined effects of body build (fat or fatness) in individuals at higher risk of excessive body fat.

Conclusions: founded on the differences acquired by the research team. We highlight that abdominal obesity is strongly connected to larger WC relate to total body gain located as excess inordinate fatness BMI or fat distribution BFP among our overall sample. Evidence, which guides us to recommend our adolescent students to intensification their hours of sports practice, in order to avoid the consequences of abdominal obesity gain. Announced in the present study as excess abdominal adiposity more metabolically active. Requiring the control of body weight loss (BFP or BMI) strongly correlates to waistline as an ideally accurate measurement of total abdominal fat (visceral \& subcutaneous). It's paired with BMI revealed their impact on body build in early adulthood or throughout life.

Keywords: belly fat, total body fat, abdominal adiposity, body composition, high school students.
\end{abstract}

\section{Introduction}

Abdomen is a complex clinical issue for the intensive care unit (ICU) and surgical teams [1]. Indicates in their difficulty to interpret the degree of intra-abdominal, visceral, or omental fat [2]. Our intervention relies on the principle that excessive amounts of subcutaneous fat or visceral fat tell us that we are overweight or even obese [3]. Unfortunately, this method requires laboratory equipment and experts to evaluate it. However, several studies have found that WC is a better indicator than WHR of abdominal visceral obesity [4]. As much as the combination of WC with a BMI explained a greater variance in non-abdominal, abdominal, subcutaneous and visceral [5]. Abdominal obesity is determined by the accumulation of both subcutaneous adipose tissue (SCAT) and visceral adipose tissue (VAT) [6].

During adolescence, males gain more central subcutaneous adipose tissue than peripheral subcutaneous adipose tissue [7], leading to high waist [8] more correlated with central obesity [9] and their health complications [10]. Sine, central obesity is more associated to body fat distribution, more than the total amount of fat in assessing the risk of developing metabolic and non-metabolic morbidities individuals according to Ana Valeria B, et al.(2014) [11]. As well as its correlation with body mass index BMI, which is positively correlated with central adiposity as preventive measures to control overweight [12] such as a widespread social phenomenon throughout the world [13].

\footnotetext{
(C) Zerf Mohammed, Atouti Noureddine,

Ben Farouk Abdullah, 2017
}

doi:10.15561/20755279.2017.0308
The case of Arabic studies which denounces the risk of overweight or obesity among adolescents (15-18 years) in Arab countries (namely, Algeria, Jordan, Kuwait, Libya, Palestine, Syria, and United Arab Emirates) that ranges from $18 \%$ to $44 \%$, for the benefit of males than females [14] in secondary schools.

Founded on this report, our intervention in this modest study, based on the indication provided by Heyward, et al. (2014) that the first step to assess the excess of body weight is to determine BMI or BFP levels. While recent studies put more emphasis on the use of waistline [15]. While some similar studies criticized its inability to distinguish subcutaneous abdominals [16] excess fat [17].

Although the new measures clinical support the hip and waist circumference as superior to BMI for predicting adjust body weight in both genders [18]. Confirm by Kyle UG, et al. BMI alone cannot provide information about the respective contribution of FFM or fat mass to body weight [19].

Whereas high WC is complementary to BMI [20] in the application of these new measures, the case of our background, which confirms that the first step to determine excess weight is to calculate ideal body weight [21] correlates to BFP or BMI levels. Account by Wener W.K. Hoeger, et al. As the recommended body weight, or the healthy weight, which requested the calculi of the percent of total body weight fat and the body composition assessment to weight management process [22].

Since the aim of this study is to estimate the impact of abdominal fat (visceral and abdominal subcutaneous adipose tissue) on body fat distribution or fatness related to the recommend weight loss among High School 
Students. Founded on the body mass index (BMI), Body Fat Percentage (BFP) and waist circumference (WC) as anthropometrics measurements inexpensive correlate to abdominal obesity as total abdominal fat (subcutaneous and visceral adipose tissue). Where to reach this goal, 100 male students from the Algerian high school, Education Sector's mandate Sidi Bel Abbes participated in the present study. Their average age $16 \pm 1.52$ years distributed into homogeneous groups, according to them, categories of body fat percent.

\section{Material and Methods}

Protocol

As the anthropometrics measurement is easy to perform in clinical practice or in the field test it is recommended by several studies based on their association with abdominal Obesity central fat deposition in adolescents, relate to the weight gain accumulation among male around the abdomen [23] stomach and waist [24] correlate to the waist circumference (WC), as the better measure of adiposity that takes into account the accumulation of abdominal fat [25]. In the opposite of visceral and abdominal subcutaneous adipose tissue, which request the imaging techniques as computed tomography and magnetic resonance imaging [26]. Reference in similar as an accurate method that cannot be used individually or day [27]. Through this review comes the importance of this study aiming to identify the effect of abdominal obesity (visceral and abdominal subcutaneous adipose tissue) on body fat distribution or fatness related to the recommend weight loss among High School Students. Where our background indicates that athletes and non-athletes students are at greater risk of obesity and overweight, the case of Algerian students mentioned in local studies [28] [29]. Confirmed by Pantelis Theodoros Nikolaidis, (2012) [30] in the evaluation of body gain target that necessities the control of body mass and fat, founded on WHO criteria as simple tool recommended for the adolescent population [26].

\section{Subjects}

The subjects were 100 male students from the Algerian high school. Their average age $16 \pm 1.52$ years distributed into homogeneous groups, depending on them, body fat percent categories. Controlled by saving tests (BMI- BFP- WC). To exclude the effect of sex on data. All subjects are male in good health, basing on their control medically. Participants were engaged through the Algerian Baccalaureate Sports exam - the state of Sidi Bel Abbes tests. All candidates in this study were voluntary to attend experience. Informed consent was obtained, and their teachers signed a document.

Testing Protocol

\section{$\checkmark \quad$ Body Fat Percentage (BFP)}

Body fat can be estimated from body mass index (BMI) [31] in the current study, we used the formula for adult: proposed by Deurenberg P, et al [31].

Adult Body Fat $\%=(1.20 \times \mathrm{BMI})+(0.23 \times$ age $)-$ (10.8 x gender) -5.4

Using gender male $=1$, female $=0$. [32]

$\checkmark$ Body mass index (BMI)

BMI was calculated as the ratio of weight (kilogram) to the square of height (meters). Obesity and overweight were classified according to WHO criteria. Adopted BMI standards considered as of $<18.5$ for underweight, normal BMI $(<25)$, obese if the BMI value was $\geq 30 \mathrm{~kg}$ / $\mathrm{m} 2$, overweight if $\mathrm{BMI} \geq 25 \mathrm{~kg} / \mathrm{m} 2$ and $<30 \mathrm{~kg} / \mathrm{m} 2$ [33].

\section{$\checkmark \quad$ Waistline (WC)}

Measure the circumference of the waist (distance around the waist) is a common measure used to check for fat held around the stomach [34]. Having extra body fat around the stomach more than $35 \mathrm{in}$. $(88 \mathrm{~cm})$ in women and more than $40 \mathrm{in.}(102 \mathrm{~cm})$ for men increase your risk of heart disease and diabetes [35].

Statistical Analyses

Data collected from the tests Table 1. Showed, that our high school students are allocated into two groups,

Table 1. Distribution of study subjects based on Body fat percentage categories.

\begin{tabular}{|c|c|c|c|c|c|c|c|}
\hline & & $\mathbf{N}$ & Mean $\pm S D$ & Shapiro-Wilk & Sig. & Levene's & Sig. $\mathrm{T}$ \\
\hline & Acceptable & 59 & $72,98 \pm 3,23$ & & & & \\
\hline \multirow{3}{*}{ Weight(kg) } & Overweight & 41 & $74,64 \pm 2,55$ & 0,96 & 0,62 & 0,48 & $0,251,020,53$ \\
\hline & Total & 100 & $73,79 \pm 2,58$ & & & & \\
\hline & Acceptable & 59 & $172,88 \pm 2,45$ & & & & \\
\hline \multirow[t]{3}{*}{ Height $(\mathrm{cm})$} & Overweight & 41 & $170,20 \pm 1,73$ & 0,96 & 0,36 & 0,37 & 0,71 1,05 0,31 \\
\hline & Total & 100 & $171,69 \pm 1,73$ & & & & \\
\hline & Acceptable & 59 & $19,82 \pm 0,47$ & & & & \\
\hline \multirow[t]{3}{*}{ BFP (\%) } & Overweight & 41 & $21,06 \pm 0,27$ & 0,92 & 0,22 & 1,01 & $0,544,440,00$ \\
\hline & Total & 100 & $20,69 \pm 2,56$ & & & & \\
\hline & Acceptable & 59 & $62,66 \pm 1,42$ & & & & \\
\hline \multirow[t]{3}{*}{$\mathrm{WC}(\mathrm{cm})$} & Overweight & 41 & $69,84 \pm 1,37$ & 0,97 & 0,56 & 1,11 & $0,193,730,00$ \\
\hline & Total & 100 & $67,90 \pm 1,11$ & & & & \\
\hline & Acceptable & 59 & $24,35 \pm 0,62$ & & & & \\
\hline \multirow[t]{2}{*}{ BMI } & Overweight & 41 & $26,45 \pm 0,72$ & 0,42 & 0,19 & 1,73 & $0,560,420,00$ \\
\hline & Total & 100 & $26,45 \pm 0,72$ & & & & \\
\hline
\end{tabular}


according to their body fat percentage categories. Based on Shapiro-Wilk and Levene's test, our total sample accepts the normative distribution and homogeneity of all variables studied. While the independent sample t-test is significant in BFP, BMI, and $\mathrm{WC}$, in the opposite of weight and height. Although the relationship between the variables selected to study was analysed by the Pearson correlations $(\mathrm{r})$. Well, $\mathrm{P}$ values $(\mathrm{P}<0.05)$ were considered statistically significant.

\section{Results}

Table 1. The Independent $\mathrm{T}$ sample t-test is not significant at $\mathrm{P} \leq 0.05$ in Age-Wight- height based on body fat classification in the opposite of BFP- BMI-WC, which are significant for the benefit of acceptable class rating (15-20) [36] in all comparisons.

View Table 2. All correlations, between abdominal obesity and upper BFP, weight or BMI are strongly positive. Where our results are in conformity with previous studies which confirm that abdominal obesity is highly correlated with large WC, upper BMI or BFP in the adolescent population [37]. Confirm by the clinic in the combined formula on behalf of BMI and WC as the best predictor of fat related to risk health in adolescents, associated with abdominal fat and total body fat as a factor altered during the process of maturation Sexuality of adolescents, according to Cecilia Lacroix de Oliveira, et al [38].

Table 2. Descriptive correlations between abdominal Belly Fat and Total Body Fat, Abdominal Adiposity, and Body Composition.

\begin{tabular}{lllll}
\hline Pearson correlation & Wight & BFP & BMI & WC \\
\hline Abdominal obesity & $0,82^{* *}$ & $0,96^{* *}$ & $0,84^{* *}$ & $1^{* *}$ \\
$\mathrm{~N}$ & 100 & & & \\
\hline & $* * \mathrm{p} \leq 0,01$ (bilateral).
\end{tabular}

\section{Discussion}

Our protocol in the present study based on Ideal Body Fat Percentages categories agreed by the American Council on Exercise (ACE), presented in Figure 1. Which shows that all means calculated are for the benefit of the overweight category, followed by acceptable. Confirms by Independent $\mathrm{T}$ in upper BFP according to the norms proposed by Dr. Marilyn P. Shieh (2012) [39] and BMI class according to WHO criteria [40]. While these results lead us to affirm the hypothesis, which confirms that more abdominal obesity is an effect of the subcutaneous fat excess relative to increasing central adiposity [41] correlates to weight composition BFP or BMI [42] ranges. Established by similar studies in the largest adipose tissue thickness in the abdominal region among male [43]. Attributed to poor lifestyles, in particular, obesity, physical inactivity, an unhealthy diet, and smoking, according to David Nieman [44]. Sight the concept, which describes the ideal body weight at a minimum essential fat [45]. We admit the indication; which agrees; to determine excess weight gain total or partial (fat or fatness); the first step is to calculate ideal body weight [21]. Largely replaced by the use of the body mass index, calculation of percent IBW as another approach used for classification of people as overweight, obese, or underweight according to Sareen $\mathrm{S}$. Gropper, et al [46]. Confirm in lower body fat correlate to the waist as better predictors of all-cause [47], the case of this study, which sustains:

a) Abdominal obesity is excess body gain correlate with total fat BMI. It highly affected body composition reported as additional excess fat among overweight category compared to the acceptable group. Confirmed by their strong correlation with measures of both total and abdominal adiposity, according to Henrike (Rianne) Joanna Cornelie Ravensbergen, et al [48].

b) Abdominal obesity is an amount deep fat correlates to total BFP. It higher influenced the distribution of total body fat reported as additional excess fat among

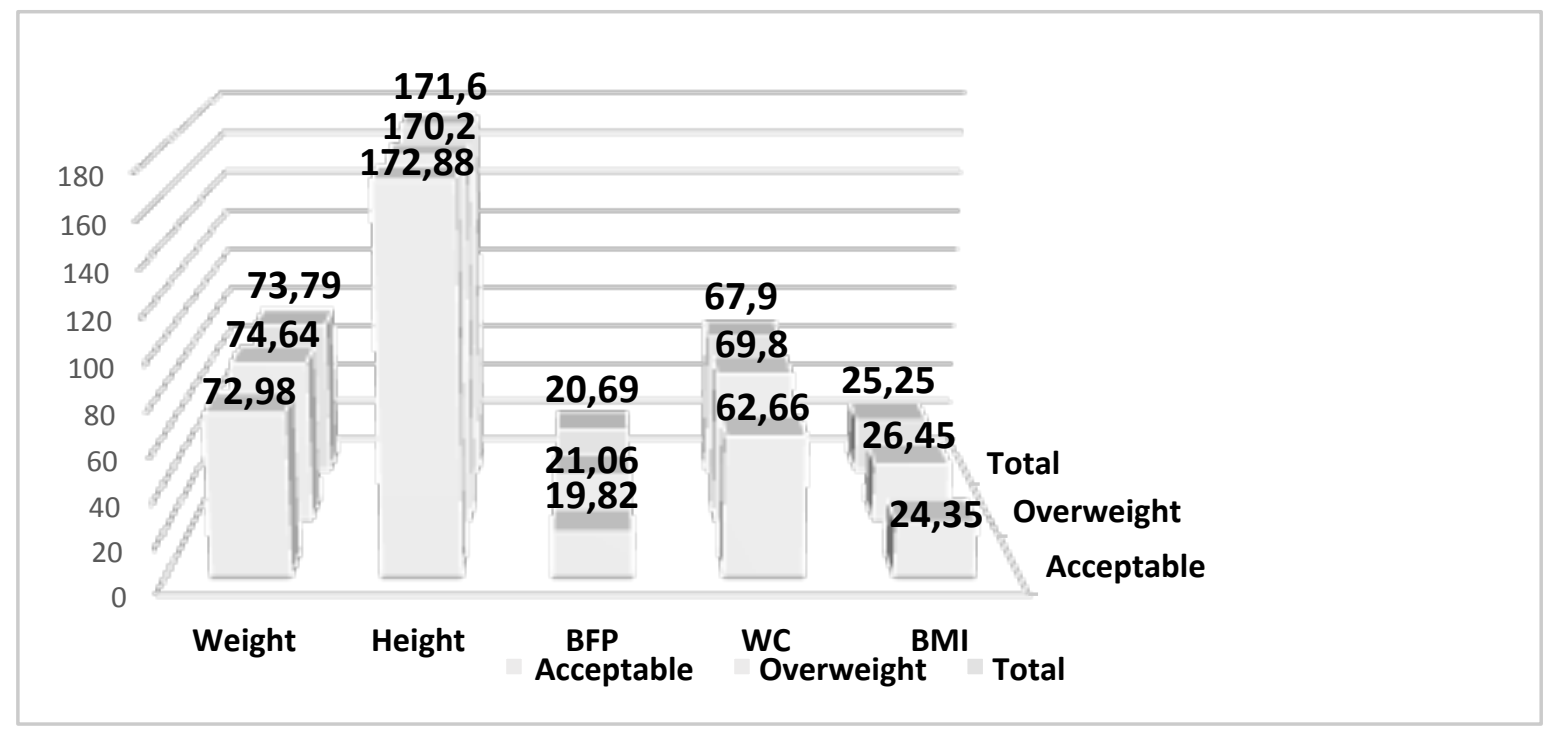

Fig 1. Presents the differences within the sample in variables chosen to study 
overweight category compared to the acceptable group. Established by Brian E Saelens, et al. As a strong expected relationship between body fat and subcutaneous abdominal fat [49, 50].

c) Waist circumference (WC) is the leading marker of abdominal fat deposits located in the central region of the body. While the combination of body mass index (BMI) and waist circumference (WC) reflects the combined effects of body build (fat or fatness) in individuals at higher risk of excessive body fat [51].

In addition to the health concerns associated with being overweight or obese during adolescence. Our results are not in conformity with statistics provided by Joseph S, et al. That female and male adolescent have similar rates of being overweight at $30.2 \%$ and $30.5 \%$ [52], established in the case of this study by statistics provided by prevalence Arabic studies, that overweight and obesity among adolescents in Arab countries are at $18 \%$ to $44 \%$ in the benefit of male than girls [53]. Due to change in Body Mass Index (BMI) correlated with abdominal obesity among adolescents stronger in boys than in girls [54]. While the most favorable rates in the case Algeria as an African continent, the statistics are in favor Libya followed by Tunisia adolescents [55].

\section{Conclusion}

Our findings support the report provides by Espen E. Spangenburg (2013) that an $8-10 \%$ decrease in body weight results in a $13-18 \%$ decrease in visceral fat and a $12-17 \%$ decrease in subcutaneous abdominal fat [56]. Confirm by Roy J Shephard (2012) that a significantly reduced in body weight (15\%) correlate to decrease of $(10 \%)$ waist circumference results in a $(28 \%)$ decrease in abdominal visceral fat to a similar degree [57]. On this basis, we agree that the recommend body weight loss is a superior predictor of healthy abdominal fat (visceral and surrounding) [58]. Interrelated to body gain excess fat or fatness, strongly associate with the large WC as an inordinate fat distribution or composition of the individual body build (overweight or obese), much warned by similar Algerian studies in this age group [29] [28]. As the proof and due to the limitations of this study, we refer to
Werner W K Hoeger that Abdominal obesity continues to increase through adolescent life, with a greater tendency toward visceral fat accumulation [59]. Confirmed by the prevalence of visceral abdominal fat in the favor of overweight fat or fatness (children or adults) as excess Waistline belly fat strongly positively correlates with the index fat or fatness, due to subcutaneous abdominal fat accumulation in the medal of the body [60]. While to interpret these results, we assumptive the percentage of hours education programs that are not adequate to sports practice due to our model educational system [61]. Although these conditions lead our students to more idle time correlate to upturn weight gain associated with the subcutaneous fat accumulation and, with age, increased visceral adipose tissue [62]. To conclude, we approve that abdominal obesity tends to increase with weight gain (BFP or BMI) strongly connected with abdominal fat associated with abdominal (subcutaneous and visceral adipose tissue). Its upper levels conduct to various diseases. Accommodated in similar studies as a critical target for the specific prevention of visceral fat accumulation through overweight students [63]. Described in the present as excess Waistline belly fat relative to weight loss (BFP or BMI) strongly correlates to waistline as an ideally close measurement of Abdominal Adiposity accumulation in the center of the body. It's paired with BMI revealed their impact on body builds fat or fatness in early adulthood or throughout life. Relative to lifestyle "Dietary Habits" vs "Time Physical inactivity" and their relations with insulin resistance, metabolic syndrome, and abnormal postprandial lipemia [64].

\section{Acknowledgments}

The authors are a grateful teacher, PE: Ben Farouk Abdullah for facilitation administrative arrangements related to the sample and Laboratory OPAPS, University of Mostaganem for their assistance in conducting this study. None of the authors has any personal or financial conflicts of interest.

\section{Conflict of interests}

The authors declare that there is no conflict of interests.

\section{References}

1. Rifat Latifi. Surgery of complex abdominal wall defects. New York, NY: Springer; 2013.

2. Melvin A Shiffman, Sid Mirrafati. Aesthetic Surgery of the Abdominal Wall. Berlin: Springer-Verlag Berlin Heidelberg; 2005.

3. Kimberly. Fowler, Flat belly yoga!: the 4-week plan to strengthen your core. Emmaus, PA: Rodale; 2013.

4. Werner W K Hoeger, Wener W K Hoeger, Sharon A Hoeger. Principles and Labs for Physical Fitness. Belmont, CA: Wadsworth Cengage Learning; 2009.

5. Barbara C Hansen, George A Bray, The metabolic syndrome: epidemiology, clinical treatment, and underlying mechanisms. Totowa, N.J: Humana; 2008.

6. Eric S Freedland. Role of a critical visceral adipose tissue threshold (CVATT) in metabolic syndrome: implications for controlling dietary carbohydrates: a review. Nutr Metab (Lond), 2004;1(12):2-4.

7. Victor R Preedy. Handbook of anthropometry: physical measures of human form in health and disease. New York: Springer; 2012.

8. Robert E Rakel. Textbook of Family Medicine. Philadelphia: Saunders/Elsevier; 2007.

9. Curtis Klaassen. Casarett \& Doull's Toxicology: The Basic Science of Poisons, Eighth Edition. USA: McGraw Hill Professional; 2013.

10.M Sibai L Nasreddine, A H Mokdad, N Adra, M Tabet, N Hwalla. Nutrition transition and cardiovascular disease risk factors in middle East and North Africa countries: reviewing the evidence. Annals of Nutrition and Metabolism, 2011;57(3-4):193-203.

11.Ana Valeria B Castro, Cathryn M Kolka, Stella P Kim, Richard 
N Bergman. Obesity, insulin resistance and comorbidities Mechanisms of association. Arq Bras Endocrinol Metabol, 2014;58(6):600-609.

12.Szer G, Kovalskysa I, De Gregorio MJ, Prevalence of overweight and obesity, and their relation to high blood pressure and central adiposity in students. Arch Argent Pediatr, 2010;108(6):492-8.

13.Mc Donald A, Bradshaw RA, Fontes F. Prevalence of obesity in panama: some risk factors and associated diseases, $B M C$ Public Health, 2015;15:1075-1080.

14.Abdulrahman O Musaiger, Mariam Al-Mannai, Reema Tayyem, Osama Al-Lalla, Essa YH Ali, Faiza Kalam, Mofida M Benhamed, Sabri Saghir, Ismail Halahleh, Zahra Djoudi, Manel Chirane1. Prevalence of Overweight and Obesity among Adolescents in Seven Arab Countries: A CrossCultural Study. Journal of Obesity, 2012;no.ID 981390:5-10.

15.Lazet Michaels Boatmon. Workout \& Worship: 8 Steps to Physical \& Spiritual Health. USA: iUniverse; 2009.

16.George A Bray, Handbook of Obesity: Volume 1: Epidemiology, Etiology, and Physiopathology, Third Edition. USA: CRC Press; 2014.

17.Christie M Ballantyne, Clinical Lipidology: A Companion to Braunwald's Heart Disease. Philadelphia, PA: Elsevier Health Sciences; 2009.

18.Abdulbari Bener, Mohammad T Yousafzai, Sarah Darwish, Abdulla OAA Al-Hamaq, Eman A Nasralla, Mohammad Abdul-Ghani. Obesity Index That Better Predict Metabolic Syndrome: Body Mass Index, Waist Circumference, Waist Hip Ratio, or Waist Height Ratio, J Obes, 2013;1:269-275.

19.Kyle UG, Schutz Y, Dupertuis YM, Pichard C. Body composition interpretation. Contributions of the fat-free mass index and the body fat mass index. Nutrition, 2003;7(8):597604.

20.Nir Y Krakauer, Jesse C Krakauer. A New Body Shape Index Predicts Mortality Hazard Independently of Body Mass Index, PLoS One, 2012;7:7:395-400.

21.Pierre Singer. Nutrition in Intensive Care Medicine: Beyond Physiology. Basel: Karger; 2013.

22. Wener WK Hoeger, ISharon A Hoeger. Principles, and Labs for Fitness and Wellness 12th. USA: Cengage Learning; 2013.

23.Edward H Thompson, Jr, Lenard W Kaye. A man's guide to healthy aging: stay smart, strong, and active. Baltimore: The Johns Hopkins University Press; 2013.

24.Frances Sizer Webb, Eleanor Noss Whitney. Nutrition: Concepts and Controversies. Belmont: Thomson/Wadsworth; 2006.

25.Waist Circumference as Compared with Body-Mass Index in Predicting Mortality from Specific Causes, PLoS One, 2011;6(4):185-192.

26.Praveen Kulkarni Nagendra, NC Ashok, D Sunil Kumar, Hugara Siddalingappa, B Madhu. World Health OrganizationBody Mass Index for Age Criteria as a Tool for Prediction of Childhood and Adolescent Morbidity: A Novel Approach in Southern Karnataka, India, Int J Prev Med, 2014;5(6):695702.

27.Brambilla P, Bedogni G, Moreno LA, Goran MI, Gutin B, Fox KR, Peters DM, Barbeau P, De Simone M, Pietrobelli A. Crossvalidation of anthropometry against magnetic resonance imaging for the assessment of visceral and subcutaneous adipose tissue in children, Int $J$ Obes (Lond), 2006;30(1):23-30.

28.Mohammed Z. Impact of Prolonged Periods Classroom Settings in Increase Intra-Abdominal Fat Area and its Consequence on Posture/Balance Control among Algerian
Childhood College Preparatory School, Phys Med Rehabil Disabil, 2017;3:016.

29.Mohammed Zerf. Impact of theoretical courses on physical health performance, BLDE Univ J Health Sci, 2016;1(1):4448.

30.Pantelis Theodoros Nikolaidis. Elevated Body Mass Index and Body Fat Percentage Are Associated with Decreased Physical Fitness in Soccer Players Aged 12-14 Years, Asian J Sports Med, 2012;3(3):168-174.

31.Deurenberg P, Weststrate AJ, Seidell CJ. Body mass index as a measure of body fatness: Age- and sex-specific prediction formulas, Br J Nutr, 1990;65:105-114.

32.Janjic Jelena, Baltic ZM, Glisic Milica, Ivanovic Jelena, Boskovic Marija, Popovic Milka, Lovrenovic Mirjana. Relationship between Body Mass Index and Body Fat Percentage among Adolescents from Serbian Republic, Journal of Childhood Obesity, 2016;1(2:10):1-5. [Online].

33.Sharon Plowman, Denise Smith. Exercise Physiology for Health, Fitness, and Performance. Philadelphia: Wolters Kluwer Health/Lippincott Williams \& Wilkins; 2008.

34.Dr Bruce Miller. Raising Disease Free Kids: Inculcate Healthy Eating Habits \& Lifestyle To Fight Diet Related Diseases. Oak Publication S/B; 2016.

35.Darwin Deen, Lisa Hark. The Complete Guide to Nutrition in Primary Care. Malden, Mass: Blackwell Pub; 2007.

36.David Magida, Melissa Rodriguez. The essentials of obstacle race training. Champaign, IL: Human Kinetics; 2017.

37.Patrícia Feliciano PereiraGisele Queiroz Carvalho, Sônia Machado Rocha Ribeiro, Hiara Miguel Stanciola Serrano,Maria do Carmo Gouveia Peluzio, Sylvia do Carmo Castro Franceschini. Measurements of body fat distribution: assessment of collinearity with body mass, adiposity and height in female adolescents, Rev. paul. pediatr, 2015;33(1):63-71.

38.Oliveira CL, Veiga GV, Sichieri R. Anthropome tric markers for cardiovascular disease risk factors among overweight adolescents, Nutrition Research., 2001;21:1335-45.

39.Dr Marilyn P Shieh. Getting Healthy With the DeVip System. US: Trafford; 2012

40.Ruth A Roth, Kathy L Wehrle. Nutrition \& diet therapy. Australia: Cengage Learning; 2017.

41.Ball GDC, Shaibi GQ, Cruz ML, Watkins MP, Weigensberg MJ, Goran MI. Insulin sensitivity, cardiorespiratory fitness, and physical activity in overweight Hispanic youth, Obes Res, 2004;12:77-85.

42.Stephen H Boutcher. High-Intensity Intermittent Exercise and Fat Loss, J Obes., 2011;1:868-870.

43.M Krotkiewski, P Björntorp, L Sjöström, U Smith. Impact of obesity on metabolism in men and women. Importance of regional adipose tissue distribution, $J$ Clin Invest, 1983;72(3):1150-1162.

44.David C Nieman. Exercise testing and prescription: a healthrelated approach. Boston: McGraw-Hill; 2007.

45.William E Garrett, Donald T Kirkendall. Exercise, and Sport Science. Philadelphia: Lippincott Williams \& Wilkins; 2000.

46.Sareen S. Gropper, Jack L. Smith, Advanced Nutrition and Human Metabolism. Belmont: Wadsworth/Cengage Learning, 2013.

47.Linda Brannon, Jess Feist. Health Psychology: An Introduction to Behavior and Health. Australia: Wadsworth, Cengage Learning; 2010.

48.Henrike (Rianne) Joanna Cornelie Ravensbergen, Scott Alexander Lear, Victoria Elizabeth Claydon. Waist Circumference Is the Best Index for Obesity-Related Cardiovascular Disease Risk in Individuals with Spinal Cord 
Injury, J Neurotrauma, 2014;31(3):292-300.

49.Brian E Saelens, Randy J Seeley, Kelly van Schaick, Lane F Donnelly, Kendall J O'Brien. Visceral abdominal fat is correlated with whole-body fat and physical activity among 8-y-old children at risk of obesity2, Am J Clin Nutr, 2007;85(1):46-53.

50.Mohammed Zerf. Body composition versus body fat percentage as predictors of posture/balance control mobility and stability among football players under 21 years. Physical education of students, 2017; 21(2): 96-102. doi:10.15561/20755279.2017.0208

51.Malara M, Kęska A, Tkaczyk J, Lutosławska G. Body shape index versus body mass index as correlates of health risk in young healthy sedentary men, J Transl Med, 2015;13(75):15.

52.Joseph S Sanfilippo, Eduardo Lara-Torre, D Keith Edmonds, Claire Templeman. Clinical Pediatric and Adolescent Gynecology. USA: CRC Press; 2009.

53.Simon Langley-Evans. Nutrition, Health, and Disease: A Lifespan Approach. Chichester: John Wiley \& Sons, Ltd; 2015.

54.Valerio G, Iafusco D, Zucchini S, Maffeis C. Study-Group on Diabetes of Italian Society of Pediatric Endocrinology and Diabetology (ISPED). Abdominal adiposity and cardiovascular risk factors in adolescents with type 1 diabetes. Diabetes Res Clin Pract. 2, Diabetes Res Clin Pract, 2012 ;97 : 99-104.

55.Tiliouine Habib Estes, Richard J. The State of Social Progress of Islamic Societies Social, Economic, Political, and Ideological Challenges. Springer: Verlag; 2016.

56.Espen E. Spangenburg. Integrative Biology of Women's Health. Dordrecht: Springer; 2013.

57.Roy J Shephard. The year book of sports medicine 2012. Philadelphia, Elsevier; 2012.

58.Viljanen AP, Lautamäki R, Järvisalo $\mathrm{M}$, Parkkola R, Huupponen R, Lehtimäki T, Rönnemaa T, Raitakari OT, Iozzo P, Nuutila P. Effects of weight loss on visceral and abdominal subcutaneous adipose tissue blood-flow and insulin-mediated glucose uptake in healthy obese subjects, Ann Med, 2009;42(2):152-60.

59. Werner W K Hoeger, Sharon A Hoeger, Amber L Fawson, Cherie I Hoeger. Fitness, and Wellness. Boston, MA: Cengage Learning; 2016.

60.Watts K, Jones TW, Davis EA, Green D. Exercise training in obese children and adolescents: current concepts, Sports Med, 2005;35:375-92.

61.Mohammed Z. Exercise is Medicine Global Health Initiative for All Ages, J Clin Epigenet, 2017;3:1:1-2.

62.Bruce M Achauer, Bahman Guyuron. Plastic Surgery: Aesthetic surgery. St. Louis: Mosby; 2000.

63.Zerf Mohammed, Mokkedes Moulay Idris, Hamek Bagdad, Houar Abelatif and Bengoua Ali. Impact of Body Composition on Optimal Competitive Body and its Consequences on Athletic Performance in Healthy Young, International Journal of Women's Health and Wellness, 2016;2(6):20-26.

64.Oren Tirosh. Liver Metabolism, and Fatty Liver Disease. UK, CRC Press: 2014.

\section{Information about the authors:}

Zerf Mohammed; http://orcid.org/0000-0001-5013-5446; biomeca.zerf@outlook.com; Physical Education Institute Laboratory OPAPS, University of Mostaganem; Avenue Hamadou Hossine, Mostaganem, 27000, Algeria.

Atouti Noureddine; http://orcid.org/0000-0002-4417-9191; attouti2476@live.fr; Physical Education Institute Laboratory OPAPS, University of Mostaganem; Avenue Hamadou Hossine, Mostaganem, 27000, Algeria.

Ben Farouk Abdullah; http://orcid.org/0000-0003-0622-8850; mohammedzerf@yahoo.com; Physical Education Institute Laboratory OPAPS, University of Mostaganem; Avenue Hamadou Hossine, Mostaganem, 27000, Algeria.

Cite this article as: Zerf Mohammed, Atouti Noureddine, Ben Farouk Abdullah. Abdominal obesity and their association with total body: fat distribution and composition. Case of Algerian teenager male high school students. Physical education of students, 2017;21(3):146-151. doi:10.15561/20755279.2017.0308

The electronic version of this article is the complete one and can be found online at: http://www.sportedu.org.ua/index.php/PES/issue/archive

This is an Open Access article distributed under the terms of the Creative Commons Attribution License, which permits unrestricted use, distribution, and reproduction in any medium, provided the original work is properly cited (http://creativecommons.org/licenses/by/4.0/deed.en).

Received: 11.04.2017

Accepted: 25.04.2017; Published: 10.05.2017 